\title{
Gastric fundal splenosis presenting as a stromal tumor and diagnosed by endoscopic ultrasound-guided SharkCore biopsy
}

The term splenosis refers to a rare condition, consisting of ectopic autotransplantation of splenic tissue into cavities of the human body or parenchymatous organs after splenic trauma or splenectomy [1]. The most frequent implantation sites include the greater omentum, the serosa of the small and large intestines, the parietal peritoneum, the mesentery, and the diaphragm. Less common sites are the liver, pancreas, stomach, bladder, gallbladder, kidney, ureter, and uterus [2]. It is usually asymptomatic, discovered incidentally during imaging or surgery. However, in some cases it has been associated with abdominal discomfort, gastrointestinal bleeding, abdominal pain, infarction of an intraperitoneal tissue nodule, and hydronephrosis due to ureteric compression [2]. Given the absence of potential malignancy, splenosis does not require follow-up or surgical treatment, except in patients who are symptomatic [3].

We report the case of a 49-year-old woman who was referred to our center complaining of abdominal bloating, dyspepsia, and gastric fullness for 2 years. Her medical history included splenec- tomy, performed in another hospital, following abdominal trauma suffered in a car accident 20 years previously, and the removal of a dysplastic nevus. Her physical examination showed no abdominal masses, only mild hepatomegaly, and no tenderness or tension. Her laboratory test results were normal.

Upper gastrointestinal endoscopy showed the presence of a round mass in the gastric fundus, measuring $20 \mathrm{~mm}$, covered by normal mucosa and of hard consistency at biopsy ( $\triangleright$ Fig. 1). Given that it was suspected that this was a gastrointestinal stromal tumor (GIST), an endoscopic ultrasound (Olympus UCT 140 linear array echoendoscope) was performed, which showed a 2-cm hypoechoic mass with smooth margins originating from the muscular layer. Doppler ultrasound showed no pathological vascularization ( $\triangleright$ Fig. 2) and a fine needle biopsy (22-gauge SharkCore needle) was taken ( Video 1).

Histological examination showed connective tissue including lymphocytes, which were also found in nodular aggregates, and lacunar spaces lined by endothelium (immunoreactive for CD34)

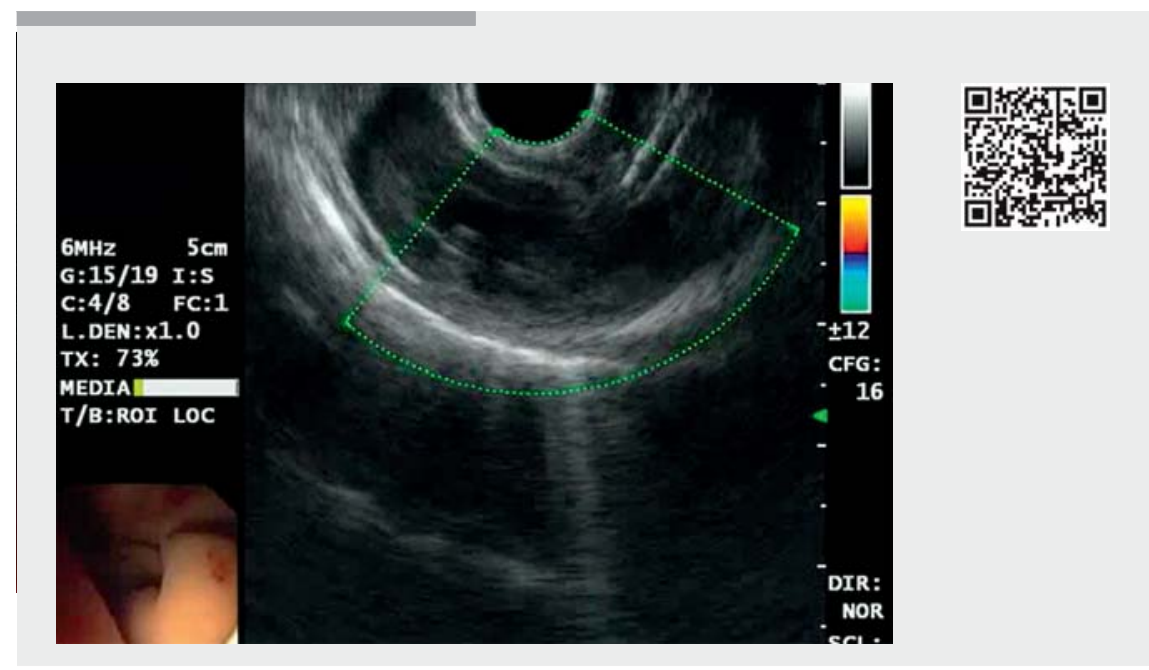

Video 1 Gastric fundal splenosis presenting as a stromal tumor and diagnosed by endoscopic ultrasound-guided SharkCore biopsy.

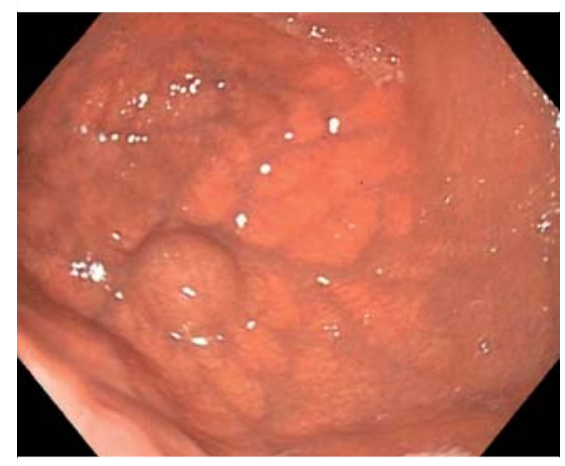

- Fig. 1 Gastroscopy image showing a $2-\mathrm{cm}$ round mass covered by normal mucosa in the gastric fundus.

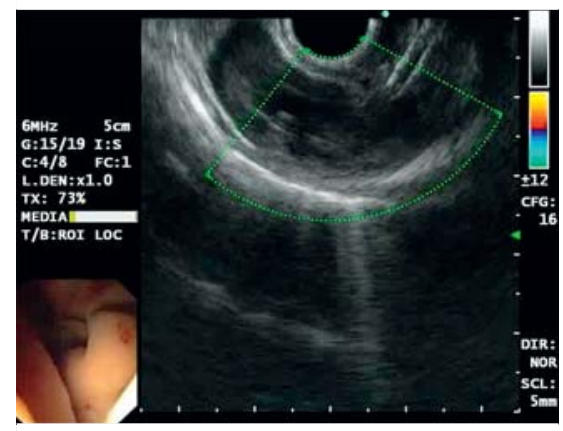

- Fig. 2 Image during endoscopic ultrasound-guided fine needle biopsy showing the 2-cm hypoechoic mass originating from the muscular layer with no pathological vascularization on Doppler examination.

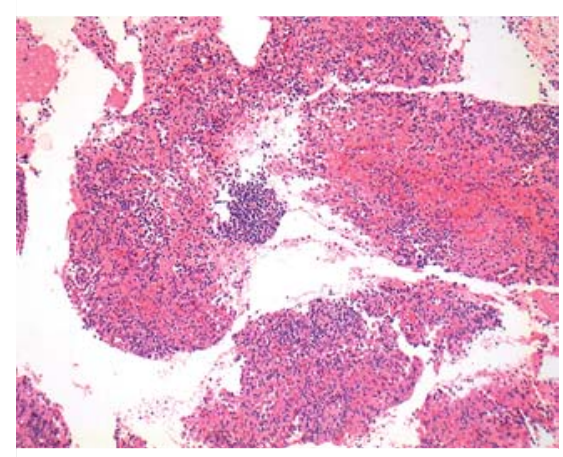

Fig. 3 Histological appearance of the biopsy showing lymphoreticular tissue including sinusoidal vascular structures, resembling splenic parenchyma (hematoxylin and eosin [H\&E] stained; original magnification $\times 20$ ). 
( Fig.3). This morphological picture was consistent with splenic tissue so, given the location of the lesion and the medical history, the diagnosis of gastric splenosis was proposed.

Endoscopy_UCTN_Code_CCL_1AB_2AD_3AF

Competing interests

None

The authors

Ilenia Barbuscio ${ }^{1}$, Alberto Fantin ${ }^{1}$, Matteo Ghisa ${ }^{1}$, Edoardo Vincenzo Savarino ${ }^{1}$, Claudia Mescoli ${ }^{2}$, Fabio Farinati ${ }^{1}$

1 Department of Surgical, Oncological and Gastroenterological Sciences (DISCOG), University Hospital of Padua, Padua, Italy

2 Surgical Pathology \& Cytopathology Unit, Department of Medicine (DIMED), University Hospital of Padua, Padua, Italy
Corresponding author

Ilenia Barbuscio, MD

Gastroenterology Unit, Department of Surgery, Oncology and Gastroenterology, University Hospital of Padua, Via Nicolò Giustiniani, 2, 35128 Padua, Italy Fax: +39-049-8212887

ilenia.barbuscio@gmail.com

\section{References}

[1] Li B, Huang Y et al. Splenosis in gastric fundus mimicking gastrointestinal stromal tumor: a report of two cases and review of the literature. Int J Clin Exp Pathol 2015; 8: $6566-6570$

[2] Ksiadzyna D, Peña AS. Abdominal splenosis. Rev Esp Enferm Dig 2011; 103: 421 - 426

[3] Li B, Huang Y, Chao B et al. Splenosis in gastric fundus mimicking gastrointestinal stromal tumor: a report of two cases and review of the literature. Int J Clin Exp Pathol 2015; 8: $6566-6570$

\section{Bibliography}

Dol https://doi.org/10.1055/a-0866-8930

Published online: 1.4.2019

Endoscopy 2019; 51: E160-E161

(c) Georg Thieme Verlag KG

Stuttgart · New York

ISSN 0013-726X

\section{ENDOSCOPY E-VIDEOS}

https://eref.thieme.de/e-videos

口回回 Endoscopy E-Videos is a free rection, reporting 回证: on interesting cases and new

techniques in gastroenterological endoscopy. All papers include a high quality video and all contributions are freely accessible online.

This section has its own submission website at https://mc.manuscriptcentral.com/e-videos 